\title{
Study on Straddled-type Monorail Vehicle Driver's Injury Caused by the Secondary Impact
}

\author{
Zhang Xiaoxu ${ }^{1}$ \\ Chongqing College of Electronic Engineering, Chongqing, 401331, China \\ 775837114@qq.com
}

Keywords: Urban traffic, Frontal crash, Computer simulation, Straddled-type monorail vehicle, Vehicle body structure, Dummy.

\begin{abstract}
Collision accidents of Monorail vehicles often result fatal injuries to the drivers, which become important subjects. Research on the safety of vehicle collision has become main study topic in the area of urban rail transit. With the development of explicit finite element technology, it is a very good choice to adopt numerical simulation test methods to do research on crash problems. It takes Chongqing straddle-type monorail vehicle as the major object. First, the finite element models of a straddle-type monorail vehicle and dummy were presented. Numerical simulations by computer have been considered as the primary means for crash simulation of vehicle body. The types of thoracic injuries, injury mechanisms, and injury tolerance were analyzed and compared with European and American standards. Achieve comprehensive and credible appraisement with the frontal crash process and crash performance.
\end{abstract}

\section{Introduction}

In recent years, with growing attention paid to the study on personal injury from different countries ${ }^{[1]}$, and the increase of hardware and software at collision aspect, the focus has been transferred to the injury caused by secondary collision. China has also carried out research on the railway transportation safety technology, and made certain progress ${ }^{[2,3]}$. But the researches are largely limited to the distortion of vehicle and analysis of energy absorption, safety analysis on the personnel - the main body on the vehicle is extraordinary less. The body of straddled-type monorail vehicle is an extremely complex system, which not only has geometric non-linearity (large displacements and deformation), but also boundary non-linearity, under the action of shock load. Therefore, when making safety analysis of personnel, the relation between the response of the injury index of driver and conductor and feature parameter of certain component is very important. In this paper, the driver is the main body, computer simulation of the head-on collision of rail vehicle is made, to analyze the injury degree of personnel at head-on collision with data, and evaluate whether the straddled-type monorail vehicle in Chongqing has met the safety demand.

\section{Appraisal standard of personnel crash injury}

At present, foreign countries have made judgment criteria on the crash injury of railway vehicle impact-resistant performance standard ${ }^{[4]}$ to railway passengers. See table 1 below: 
Table1 Comparison of passenger injury criteria

\begin{tabular}{|c|c|c|c|c|}
\hline \multicolumn{2}{|r|}{ Injury criterion } & \multirow{2}{*}{$\begin{array}{l}\text { England ATOC } \\
\text { AV/ST9001 }\end{array}$} & \multirow[t]{2}{*}{ ECE R94 } & \multirow{2}{*}{$\begin{array}{c}\text { American } \\
\text { FMVSS208 } \\
\text { Mail }\end{array}$} \\
\hline & & & & \\
\hline Head & HIC/HPC36 & 500 & $1000\left[\mathrm{HPC}_{36}\right]$ & $700\left[\begin{array}{ll}\mathrm{HIC}_{15} & \end{array}\right]$ \\
\hline \multirow[t]{2}{*}{ Neck } & Neck in flexion[Nm] & 190 & \multirow{2}{*}{$\begin{array}{l}57 \text { Nm(bending } \\
\text { moment of Y axis) }\end{array}$} & 310 \\
\hline & Neck in extension[Nm] & 57 & & 135 \\
\hline \multirow[t]{2}{*}{ Chest } & $60 \mathrm{~g}[3 \mathrm{~ms}]$ & & & $60 \mathrm{~g}$ \\
\hline & $\begin{array}{l}\text { sternum compression } \\
\text { amount }[\mathrm{mm}]\end{array}$ & & 50 & 63 \\
\hline Leg & $\mathrm{FPC}[\mathrm{N}]$ & 4000 & 7580 & 10000 \\
\hline
\end{tabular}

Over the years, head injuries are considered the most severe injury to human body in traffic accidents. Head and thoracic injuries are difficult to be healed, and can lead to long-term physical dysfunction, so cerebral injury have always been the key of passenger injury research. Currently, head injury criterion (abbreviated as HIC) is the most widely used damage criterion

${ }^{[5]}$. The computational formula is:

$$
H I C=\max \left(t_{2}-t_{1}\right)\left(\frac{1}{t_{2}-t_{1}} \int_{1}^{t_{2}} a(t) d t\right)^{2.5}<1000
$$

In the formula: $\mathrm{t} 1$ and $\mathrm{t} 2$ are respectively the beginning and ending time point to make the HIC reach the maximum pulse, and the unit is ms; $a(t)$ is resultant acceleration with the unit of $g$.

In addition, if the thorax acceleration exceeds the limit of human body, it will be fatal injury. The earliest physical evaluation criterion of head-on collision thoracic injury is the sternum compression amount, namely, if the sternum deflection exceeds the maximum amount of compression, it is identified to be likely to cause injury to the chest. The specified value in the laws and regulations of China is $\leq 75 \mathrm{~mm}$. The chest structure is complex; the injury condition of chest cannot be accurately estimated relying only on the chest compression amount. Therefore, some European and American countries also refer to other parameters, with the general requirements on passengers of no more than $60 \mathrm{~g}$ of resultant acceleration at the chest, and no more than $3 \mathrm{~ms}$ of lasting action time. The computational formula for thoracic injury probability of above AIS3 level and amount of compression of the chest and $3 \mathrm{~ms}$ of resultant acceleration at chest is:

$$
P\left(A I S_{3+}\right)=\frac{1}{1+e^{-c}}
$$

In the formula $C=6.43+0.07 A_{s}+0.063, A_{s}$ is $3 \mathrm{~ms}$ resultant acceleration at chest $(\mathrm{g})$;

\section{The establishment of secondary collision simulation model}

In recent years, with the rapid development of computer hardware and software technology, computing power has been greatly improved. So, the FEM technology has been applied 
widely in the field of rail vehicle collision, to improve various methods, and increase the security design of vehicle crash.

\section{The establishment of rail vehicle body model}

Take the factor of alleviating the injury degree of drivers as the main consideration of establishing rail vehicle car body structure. The body of the rail vehicle mainly adopts modularized design, to decompose the complete vehicle structure into a number of separate but interrelated modules ${ }^{[6]}$, as shown in Figure 1 below.

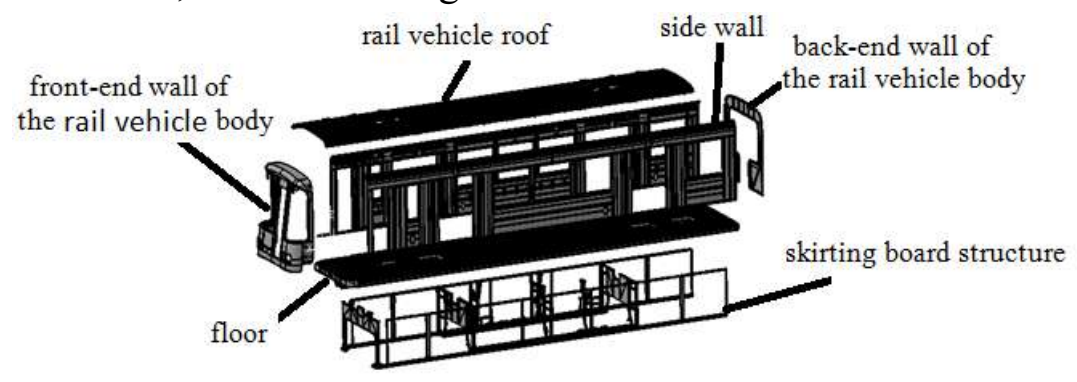

Fig. 1 modular design application in straddled-type monorail vehicle body

After the body CAD model is completed, the finite element model of the rail vehicle body structure shall be established. The CAE finite element model is different from CAD structural model, which reflects the exact shape of the mode and the characteristics of the components (including specific equipment tolerance and so on), but CAE doesn't need to describe all the characteristics of the model, so the first thing should be done is structure optimization and geometry cleanup of the model. Import the CAD data model into finite element analysis software. The body structure is usually sheet metal template, and the method of taking out middle surface is often adopted. Then treat the middle surface with geometry cleanup method, by getting rid of tiny features (chamfering, rounding, small protruding stage, technical hole and so on) and simplifying the areas without distortion or not affected by forces, to save calculating time and cost. And then strictly comply with requirements on finite element mesh division, to divide 2-d mesh units and divide the entity parts into hexahedron or tetrahedron units. Then use the mesh optimization algorithm in the software to make mesh optimization. The quality of $2 \mathrm{~d}$ or $3 \mathrm{~d}$ meshes will directly affect the computational accuracy. Unqualified mesh quality will make the calculation of structure failed to be carried out. In the head car model of rail vehicle, the body mainly adopts shell element mesh, and corresponding refining is made on the mesh of parts with collision energy absorbing and stress concentration. For the systems of the car body, like air conditioner and the kind, specific deformation shall not be taken into account, and the contour feature shall be reserved, and then conduct balance-weight treatment. The connections between the components are welding spots, and the finite element model of the head car of straddle-type monorail vehicle is shown in figure 2, with 484,760 units and 472,828 nodes.

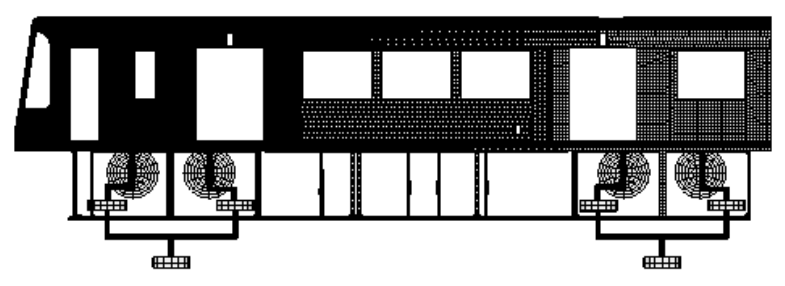

Fig.2 Finite element model of the first straddled-type monorail vehicle body 


\section{Simulating the establishment of dummy}

Simulation dummy structure consists of six parts: head, neck, chest, arms, waist and abdomen and legs. According to the standard body size of ergonomics and anthropometric reference system, to determine the 50th percentile size parameters and joint design concept of adult male. Size parameters are as follows (see table 2 ).

Table 2 Size Parameters of Mannequin [mm]

\begin{tabular}{l|l|l|l|l|l|l|l|l}
\hline $\begin{array}{l}\text { Head } \\
\text { length }\end{array}$ & $\begin{array}{l}\text { head } \\
\text { width }\end{array}$ & $\begin{array}{l}\text { head } \\
\text { height }\end{array}$ & $\begin{array}{l}\text { forearm } \\
\text { length }\end{array}$ & $\begin{array}{l}\text { rear } \\
\text { arm } \\
\text { length }\end{array}$ & $\begin{array}{l}\text { hand } \\
\text { length }\end{array}$ & $\begin{array}{l}\text { thigh } \\
\text { length }\end{array}$ & $\begin{array}{l}\text { crus } \\
\text { length }\end{array}$ & $\begin{array}{l}\text { feet } \\
\text { length }\end{array}$ \\
\hline$\leq 184$ & $\leq 154$ & 223 & 313 & 294 & 183 & 460 & 369 & 247 \\
\hline
\end{tabular}

Make viscoelastic simulation of the neck head skin, lumbar, and rib muscle. Plastic material is used to simulate the rib, thoracic spine and feet, elastic material is used to simulate human organ and muscles of the limbs, low-density foamy material is used to simulate the chest and hip of the body, hollow material is used to simulate the body chest and neck skin, rigid material is used to simulate skeleton and sensor. Other parts of the anthropometric dummy are connected by the hinge. HybridIII50th-type dummy finite element model on test basis is seen in figure 3 .

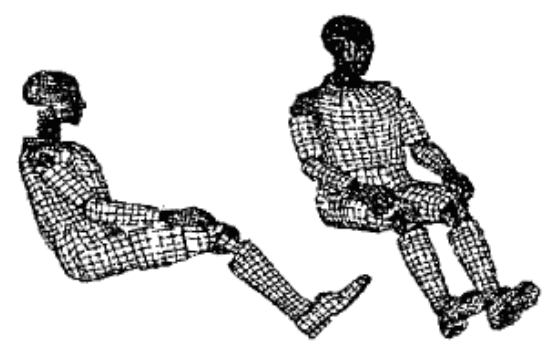

Fig.3 Finite Element dummy model

Adjust the sitting posture of the dummy, and then integrate the dummy with bodywork model. The whole model is seen in Figure 4.

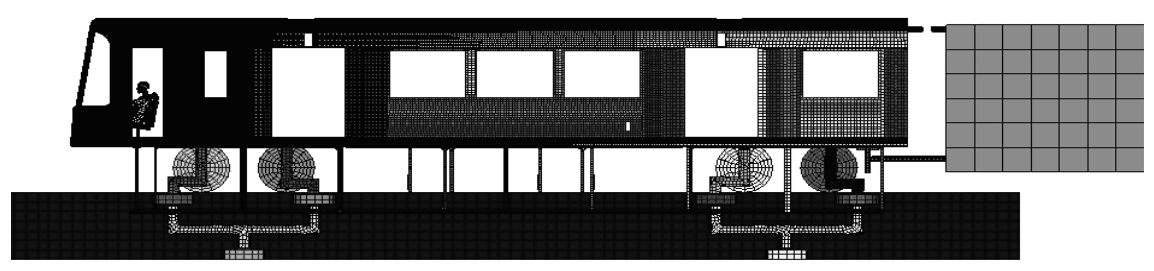

Fig.4 Finite element model of vehicle including dummy

\section{Driver Injury Analysis}

\section{The response of the human body}

Figure 5 is about the movement of drivers with safety belt fastened at the collision. At the first stage, from the start of collision to the $5 \mathrm{~ms}$ of collision, there is no collision between the car body and rigid wall, and the distortion of car head is 0 , the body of driver will move forward at a speed similar to the initial speed in driving direction, with a throwing trend in collision direction. At $5 \mathrm{~ms}$, the head of straddled-type monorail vehicle is hit by obstacles, with the distortion becoming gradually serious. After the collision time lasts to 10milliseconds, certain distortion can be seen on the car head, and the human body still 
moves forward because of inertia force, but restricted by the safety belt in the moving process, thus relative velocity occurs between the car body and the driver at that moment. Until $45 \mathrm{~ms}$, the maximum deformation is $101 \mathrm{~mm}$ (see figure 6), at the same time of the car collision, the human body moves forward further, with the head in declining tendency. In the following period of time, the distortion of car head slightly changes and basically preserves the largest distortion, because the collision energy is decentralized successfully through body frame, and it is found through body response analysis that at 70 milliseconds of collision, body curling occurs, different degrees of damage is caused to the head, neck, waist and chest. At 100 milliseconds, it can be seen from the figure that the bending degree of waist, chest, neck and legs of the human body becomes better with spring-back. In the entire process of collision, the distortion of the guide mechanism of straddled-type monorail vehicle is also very large, with swings in the front and at the back, the cab at head car of rail vehicle and walls at the left and right and the front of car roof and undercarriage all have obvious plastic deformation in the collision process. A lot of energy is absorbed, which is helpful to ease the injury value.

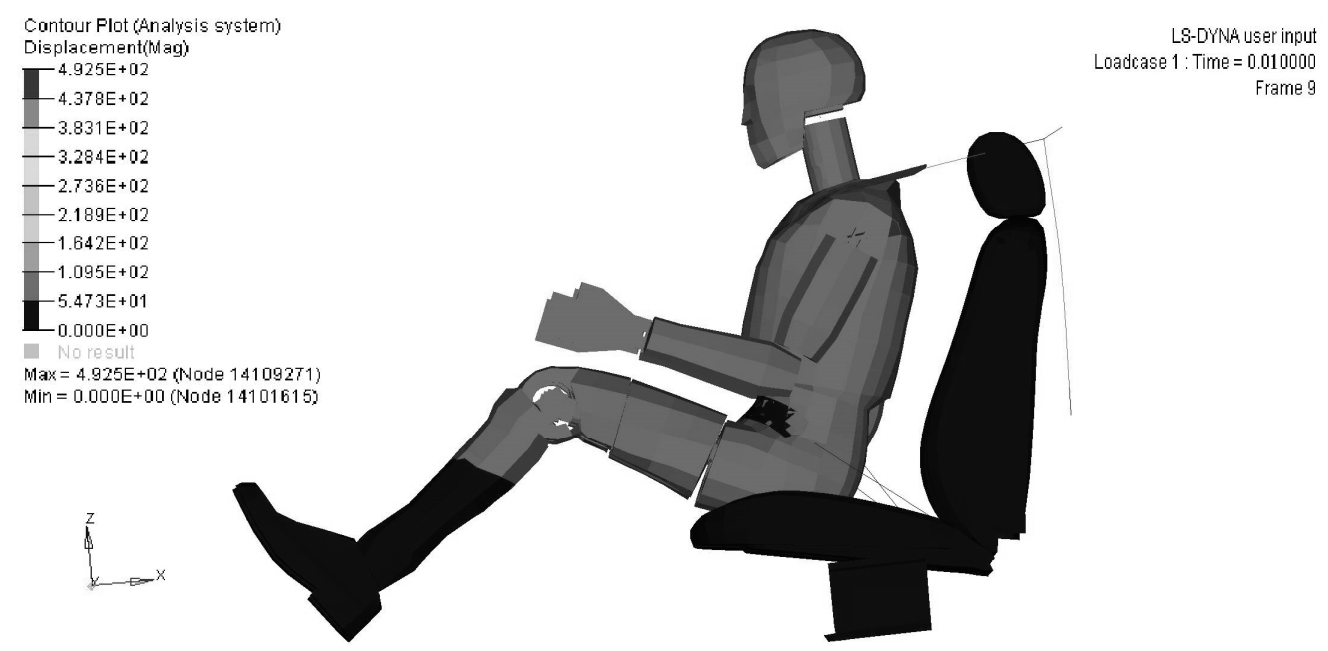

a) $\mathrm{t}=10 \mathrm{~ms}$

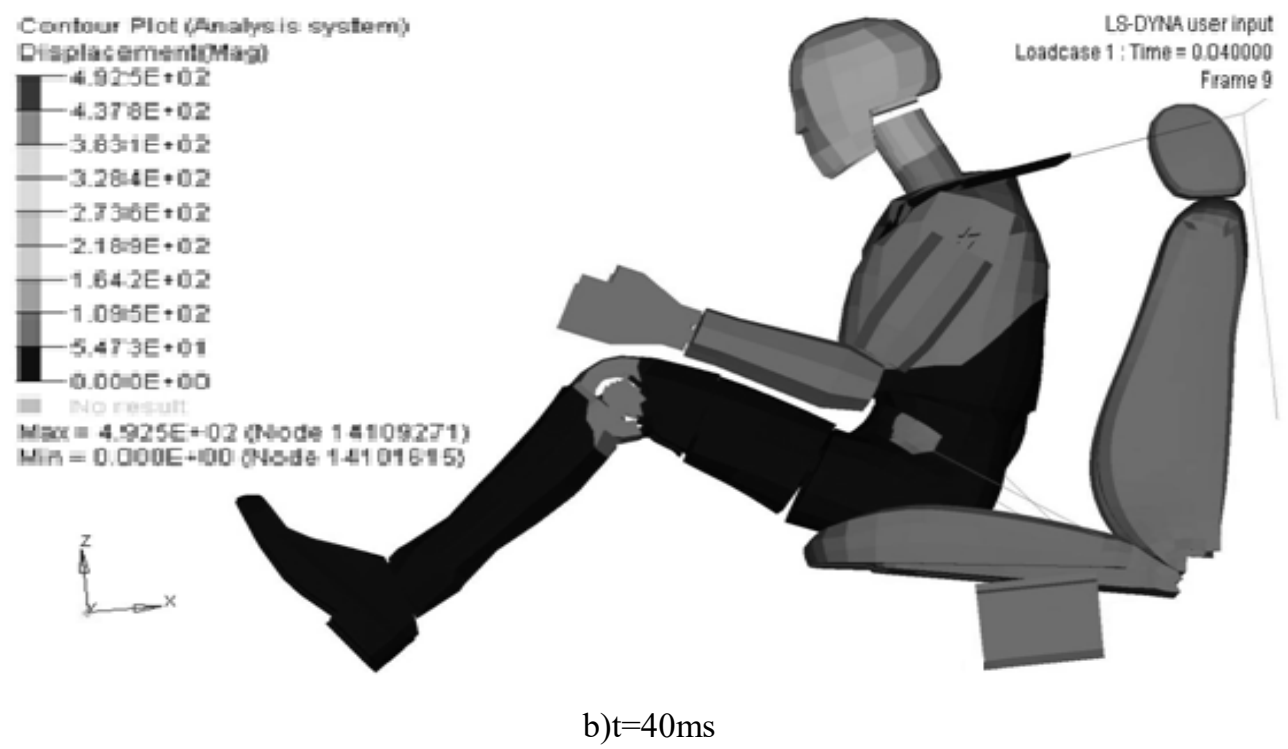


Contour Put chulysis sintertio Displacementomal:

T 4 9.2E +02

$-4.379 E+02$

$-3.831 \mathrm{E}+02$

$-3784 E+02$

- $2756 \mathrm{Ead}$

- $2.18 \mathrm{~g}$ Eैat

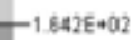

$-1.005 E+02$

$-5.473 E+01$

$-0.000 E+00$

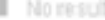

$\operatorname{vex}=4.925 E \cdot 02$ (owode 1410927 )

Wain : $0.000 \mathrm{E}-0.0$ ONede 14101615 ?

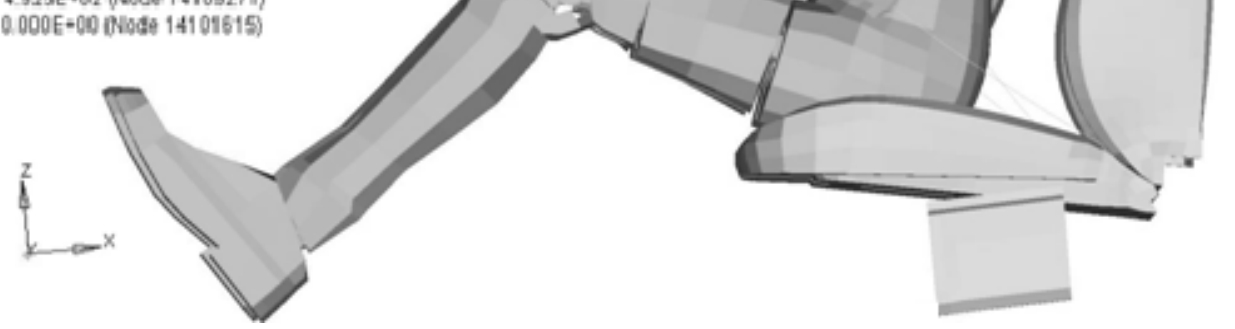

c) $\mathrm{t}=70 \mathrm{~ms}$

Contour Plot Analysis sylem

Displacemetoves:
T.925E 02
-4.378E.02
- $3.831 E \cdot 02$
$-3.234 \mathrm{E} \cdot 02$
$-2736 \mathrm{0} \cdot 02$
$-21006 \cdot 02$
$-16420 \cdot 02$
$-1.0086 \cdot 02$
$-547 x \cdot 01$
- $0.000 \mathrm{E} \cdot 00$
Mar $=4$ 92sE-02 OVode 141 09271)
En $=0.000$ t -00 ovode 14101615

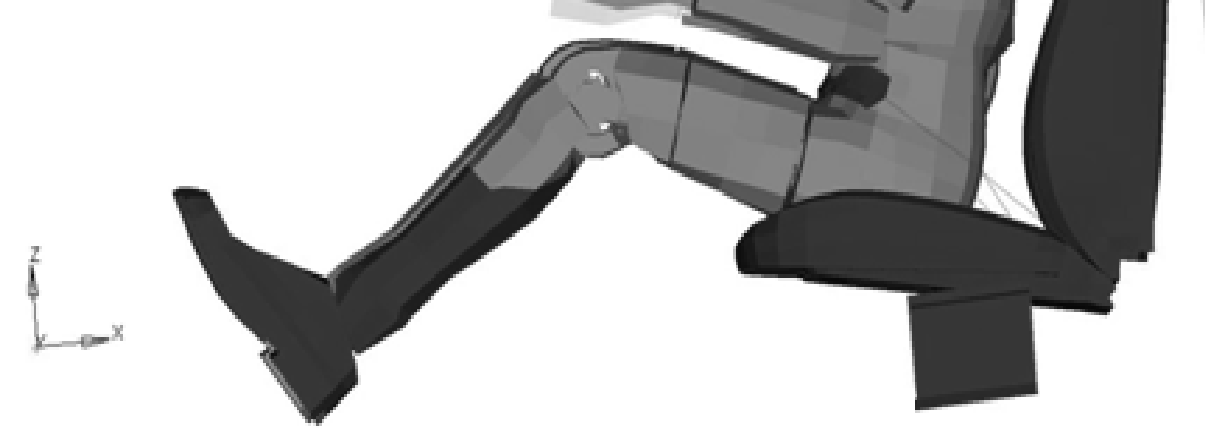

d)t $=100 \mathrm{~ms}$

Figure5 The response of dummy 


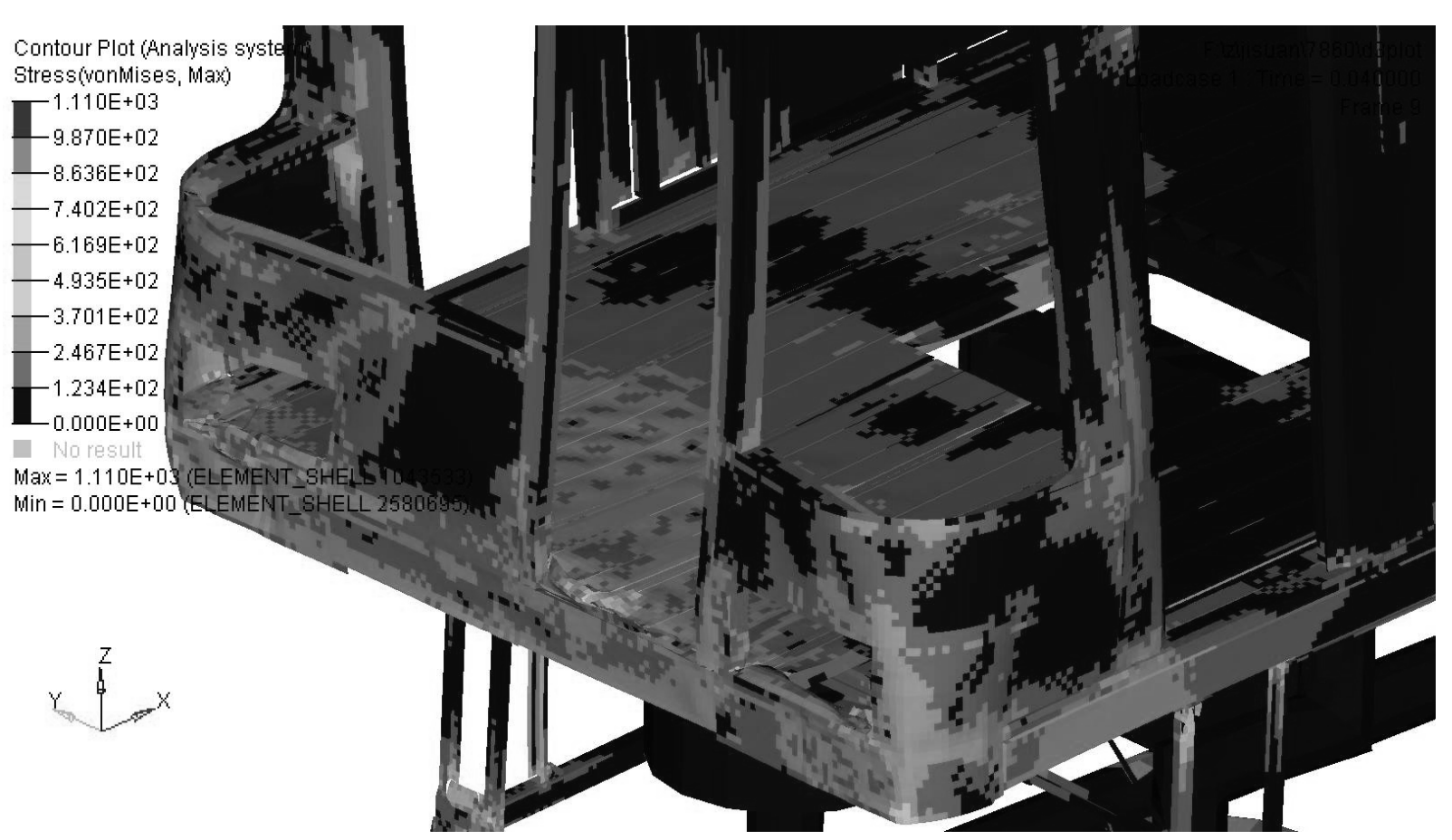

Figure6 Deformation of the front vehicle body at $45 \mathrm{~ms}$

\section{Body injury}

The damage value of dummy obtained according to the simulation analysis calculation is shown in figure 7.

It can be seen from the motion track of dummy obtained by the simulation and figure 7 that: at the maximum deformation of the body, the acceleration of the acceleration reaches the peak, with the biggest acceleration of 670, and the HIC value of the head of passenger is 562 by calculation. Because the dummy leaves the backrest, and the motion space is big, the acceleration increases rapidly. Due to protection from safety belt, the injury degree is still below permissible value, although it is slightly higher. Thereafter, the body deformation levels off and the injury degree of the head is gradually weakened.

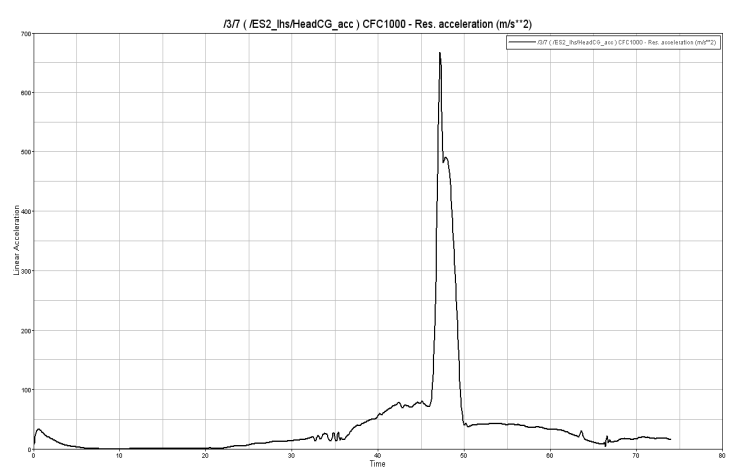

a) the curve of accelerant severity

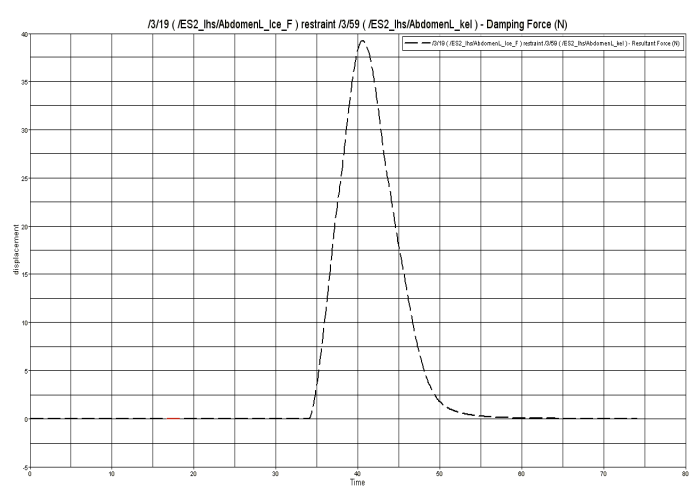

b) Curve of the thorax compression rate

As can be seen from figure $b$ that the maximum amount of compression of the chest is $38 \mathrm{~mm}$, which is below the injury criteria(sternum compression amount in the laws and regulations of China $\leqslant 43 \mathrm{~mm}$ ) of lowest amount of compression of the chest in direct impact, which is within an acceptable range, and the body chest has lower injury degree. 


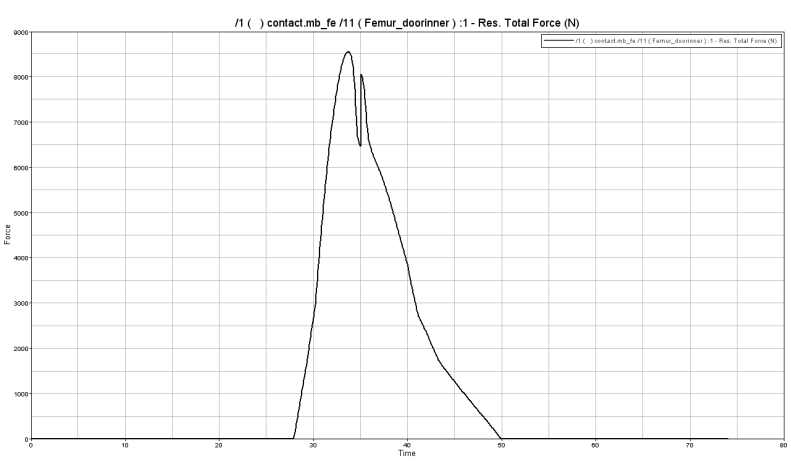

c) Strength curve of leg

Figure 7 Damage variable of dummy

Figure c shown that the thigh force is $8500 \mathrm{~N}$. That the injury value of the leg is high is somewhat related to the multi-body model of dummy. Although the injury value doesn't exceed American standard, no fatal threat will occur. While, the injury criterion is still high enough than have the potential possibility of getting injured.

According to the analysis of the damage value of human body, there is still distance between each damage value and the regulatory threshold. It is just because that the thigh force is bigger, while still meets the regulatory requirements, which proves that the driver is quite safe in the head-on collision of the vehicle structure.

\section{Summary}

With the safety analysis of head-on collision of straddled-type monorail vehicle as the research objective, and driver as the research object, corresponding finite element collision analysis software is used to establish rational head-on collision simulation model of all-shell-element unit, and computational simulation is made, it can be seen from the car body deformation that the crash-worthiness of the vehicle is quite acceptable, able to absorb collision energy through front end distortion; through analysis of the casualty from the response and damage condition, conclusion is made that the safety of the vehicle can be ensured at head-on collision.

\section{References}

[1]Lu G, Energy absorption requirement for crashworthy vehicles, IMechE, 2002,216(1)31-39.

[2] Zhao Tang, Feng Jia Liu, Shi Hui Guo, Jiao Chang and Jian Jun Zhang, Advances in Mechanical Engineering.2016,Vol.8(4)1-13.

[3] YAO S, TIAN HQ. crash research on thin-shelled structure as vehicle energy-absorbing components [J]. china railway science,2001,22(2):55-60.

[4] LU G D. The bumping resistance design for rolling stock. Rolling Stock, 2007,45 (10) : $1-5$.

[5] WANG W B, ZHAO H L, LIU X J. Railway Vehicle Occupant's Injury Caused by the Impact Second[J].urban mass transit,2007,10(9):23-27. 